\title{
Association of $n-3$ and $n-6$ long-chain polyunsaturated fatty acids in plasma lipid classes with inflammatory bowel diseases
}

\author{
Mária Figler ${ }^{1}$, Beata Gasztonyi ${ }^{1}$, Judit Cseh $^{2}$, Gábor Horváth ${ }^{3}$, Andrea G. Kisbenedek ${ }^{3}$, Szilvia Bokor ${ }^{4}$ and \\ Tamás Decsi ${ }^{4}$ \\ ${ }^{1}$ First Department of Internal Medicine, University of Pécs, Ifjusag u. 13., 7624 Pécs, Hungary \\ ${ }^{2}$ Second Department of Internal Medicine, University of Pécs, Pacsirta u. 1. 7624 Pécs, Hungary \\ ${ }^{3}$ Institute of Nutrition and Dietetics, Faculty of Health Sciences, University of Pécs, Vörösmarty u. 4. 7621 Pécs, Hungary \\ ${ }^{4}$ Department of Paediatrics, University of Pécs, József Attila u. 7.7623 Pécs, Hungary
}

(Received 20 June 2006 - Revised 15 November 2006 - Accepted 3 January 2007)

In order to establish the biochemical basis for dietary interventions, we investigated the fatty acid composition of plasma lipid classes in patients with inactive inflammatory bowel disease. In this cross-sectional study thirty patients with ulcerative colitis (UC), twenty-one with Crohn disease (CD) and twenty-four controls were investigated (mean age: UC, 40.8 (SD 12.1); CD, 37.6 (SD 11.0); control, 31.5 (SD 8.4) years). Fatty acid composition of plasma lipids was determined by high-resolution capillary GLC. In plasma phospholipids, significantly higher values of eicosapentaenoic (20:5n-3), docosapentaenoic (22:5n-3) and $\gamma$-linolenic $(18: 3 n-6)$ acids were found in control patients and patients with UC as compared to patients with CD [median \% (weight by weight), control $v$. UC $v$. CD $: 20: 5 n-3,0.09$ (interquartile range (IQR) 0.05 ) $v .0 \cdot 14$ (IQR $0 \cdot 10$ ) $v .0 \cdot 16$ (IQR 0.10), $P<0.05 ; 22: 5 n-3,0.14$ (IQR 0.10) v. 0.27 (IQR 0.16) v. 0.31 (IQR 0.10), $P<0.001 ; 18: 3 n-6,0.02$ (IQR 0.02) v. 0.03 (IQR 0.02) v. 0.05 (IQR 0.03), $P<0.05$ ]. When compared to the control, values of the principal $n-3$ and $n-6$ long-chain PUFA, arachidonic acid (20:4n-6) and DHA $(22: 6 n-3)$ were significantly higher in patients with UC but not in patients with CD [median \% (w/w), UC v. control: $20: 4 n-6,8.43$ (IQR 3.23) v. 6.92 (IQR 2.96), $P<0.05 ; 22: 6 n-3,1.22$ (IQR 0.56) v. 0.73 (IQR 0.39), $P<0.05$ ]. As seen there are considerable differences between the long-chain PUFA status of patients suffering from UC or CD. The data obtained in the present study do not support the concept of eicosapentaenoic acid or DHA deficiency in patients with either UC or CD.

Crohn disease: Inflammatory bowel disease: Polyunsaturated fatty acids: Ulcerative colitis

Our knowledge concerning the primary cause and aetiology of inflammatory bowel disease (IBD) is still limited; like in many chronic diseases, the aetiology appears to be multifactorial.

Recent evidence indicates that disturbances of fatty acid status may be among the metabolic consequences of IBD. In patients with IBD, malnutrition develops as a result of reduced energy or protein intake or as a consequence of losing nutrients, or as a combination of these factors (Han et al. 1999). On the one hand, malnutrition has been associated with essential fatty acid deficiency (Decsi et al. 1998) and, on the other hand, epidemiologic studies suggest that PUFA may figure in the pathophysiology of IBD (Shoda et al. 1996).

The $n$-3 PUFA, eicosapentaenoic acid (20:5n-3), serves as a precursor of eicosanoids with limited inflammatory effects; moreover, abundant availability of $20: 5 n-3$ reduces the production of the pro-inflammatory 2-series eicosanoids generated from arachidonic acid (20:4n-6; Belluzzi, 2004). In addition, $n$-3 PUFA including DHA (22:6n-3) regulate the production of some inflammatory cytokines and down-regulate the expression of a number of genes involved in inflammation (Teitelbaum \& Walker, 2001; Gil, 2002); hence, changes in metabolism of $n$-3 PUFA may be of relevance in the activity of the chronic inflammatory processes in IBD.

Modification of the inflammatory process in IBD via altering the availability of the eicosanoid precursor PUFA may offer clinical benefits for the patients. However, only a few studies have addressed the question of the availability of fatty acids in patients with ulcerative colitis (UC) or Crohn disease (CD), and most studies (Esteve-Comas et al. 1992, 1993; Kuroki et al. 1997) analysed only total plasma lipid composition which is a less reliable indicator of essential fatty acid status than fatty acid composition of individual plasma lipid classes. To the best of our knowledge, the present study is the first to describe the fatty acid composition of plasma NEFA, phospholipids (PL), sterol esters and TAG lipids in patients with IBD.

\section{Patients and methods}

In this cross-sectional study thirty patients with inactive $\mathrm{UC}$ and twenty-one with $\mathrm{CD}$ as well as twenty-four carefully selected, clinically healthy, age-, sex-, weight- and

\footnotetext{
Abbreviations: CD, Crohn disease; IBD, inflammatory bowel disease; LCPUFA, long-chain PUFA; PL, phospholipids; UC, ulcerative colitis.

* Corresponding author: Dr Mária Figler, fax 003672536148, email maria.figler@aok.pte.hu
} 
height-matched control subjects were investigated in the First Department of Internal Medicine of the University of Pécs, Pécs, Hungary. The study was carried out in accordance with the Declaration of Helsinki II and with approval of the ethics committee of the University of Pécs. Informed written consent was obtained from each patient and control subject.

The diagnosis of UC or CD was based on histological investigations in all cases. At the time of the study, all patients were on a normal diet and no special dietary intervention was followed. Disease activity was controlled by small-dose maintenance therapy (4-8 mg methilprednisolon/d and 250-750 mg sulfasalasine/d). Members of the control group included health care providers (nurses, physicians, medical students, laboratory assistants) who received no medication and had no history of suffering from lipid disorders or absorption insufficiencies. The diet of the control subjects was assessed by a trained dietitian. The controls followed the common Hungarian diet (energy intake $9-9.5 \mathrm{MJ} / \mathrm{d}$; protein $15-20 \%$; carbohydrates 45-55\%; lipids 30-35\%). Dietary histories regarding a 4-week-long period prior to the study revealed no significant differences between the energy, macro- and micronutrient intakes of the controls and IBD patients.

Anthropometric measurements were carried out by the same investigator. Body height and weight were measured in the survey unit with validated medical care instruments, and BMI was computed as weight $(\mathrm{kg})$ divided by squared height $\left(\mathrm{m}^{2}\right)$.

Both in the healthy control subjects and IBD patients, venous blood samples were taken from the antecubital vein into tubes containing $2 \mathrm{mg} / \mathrm{ml}$ EDTA as anticoagulant between 08.00 and 08.30 hours, after an overnight fast. This strict postalimental time schedule was maintained in order to preclude the diet-induced dynamic changes of plasma fatty acids. The plasma was removed within $30 \mathrm{~min}$ and stored at $-80^{\circ} \mathrm{C}$ until analysis. All samples were thawed only once.

TAG and cholesterol were determined with an enzymatic kit (Boehringer Mannheim, Mannheim, Germany). HDLcholesterol was measured by the precipitation method of Steele et al. (1976). Platelet number was determined with an automatic cell counter (Celldyn 3700 Abbott optical LASER) and C-reactive protein concentrations with the LASER nepherlometric Beckman Immage machine in the Clinical Biochemical Institute of the University of Pécs, Pécs, Hungary.

Fatty acid analyses were carried out in the Department of Paediatrics, University of Pécs, Pécs, Hungary. For the analysis of plasma fatty acid profiles, plasma samples were melted and lipids were extracted by the addition of $3 \mathrm{ml}$ chloroform and $1 \mathrm{ml}$ methanol. The mixture was shaked vortically at $2000 \mathrm{rpm}$ for $10 \mathrm{~min}$, the underlayer was aspirated into vials and evaporated under nitrogen stream. The four fatty acid internal standards (dipentadecanoil acid, tripentadecanoin acid, cholesteryl-pentadecanoate acid and pentadecanoic acid) were added. All vials were reconstituted in $70 \mu \mathrm{l}$ chloroform. The solvents for TLC of plasma lipids were as follows: hexane-diethyl ether-chloroform-acetic acid (21:6:3:1, by vol.) followed by chloroform-methanol-water $(65: 25: 4$, by vol.). The bands were stained with dichlorofluorescein, removed by scraping and transesterified in $3 \mathrm{M}-\mathrm{HCl}-$ methanol solution at $84^{\circ} \mathrm{C}$ for $45 \mathrm{~min}$.

Fatty acids were analysed by high-resolution capillary GLC using a Finnigan 9001 gas chromatograph (Finnigan/
Tremetrics Inc., Austin, TX, USA) with split injection (ratio of 1:25), automatic sampler (A200SE; CTC Analytic, Zwingen, Switzerland) and flame-ionisation detector with a DB-23 cyanopropyl column of $40 \mathrm{~m}$ length (J \& W Scientific, Folsom, CA, USA). The temperature programme was the following: temperature of injector at $80^{\circ} \mathrm{C}$ for $0.1 \mathrm{~min}$, temperature increase by $180^{\circ} \mathrm{C} / \mathrm{min}$ up to $280^{\circ} \mathrm{C}$, temperature of detector at $280^{\circ} \mathrm{C}$, temperature of column area at $60^{\circ} \mathrm{C}$ for $0.2 \mathrm{~min}$, temperature increase by $40^{\circ} \mathrm{C} / \mathrm{min}$ up to $180^{\circ} \mathrm{C}$, $5 \mathrm{~min}$ isotherm period, temperature increase by $1.5^{\circ} \mathrm{C} / \mathrm{min}$ up to $200^{\circ} \mathrm{C}, 8.5 \mathrm{~min}$ isotherm period, temperature increase by $40^{\circ} \mathrm{C} / \mathrm{min}$ up to $240^{\circ} \mathrm{C}$ and $13 \mathrm{~min}$ isotherm period. The constant linear velocity was $0 \cdot 3 \mathrm{~m} / \mathrm{s}$ (referred to $100^{\circ} \mathrm{C}$ ). Peak identification was verified by comparison with authentic standards. Fatty acid results were expressed as percentages (weight by weight) of fatty acids detected with a chain length between twelve and twenty-four carbon atoms.

\section{Statistical analysis}

Results were evaluated with SPSS for Windows, release 11.5 (SPSS Inc., Chicago, IL, USA). All data except fatty acids are presented as means and standard deviations and were evaluated by ANOVA followed by the least significant difference comparison test to compare mean values of subgroups. The fatty acid data are presented as median and range from the first to the third quartile values, because skewed distributions were found in several parameters, especially in fatty acids present at low concentrations. Fatty acids were analysed by the Kruskal-Wallis non-parametric ANOVA followed by Mann-Whitney's two-sided rank test to compare median values of subgroups. Results were regarded as statistically significant at $P<0.05$.

\section{Results}

The clinical features of the study subjects are shown in Table 1. The ages of the patients with UC were significantly higher than those of the controls. In patients with $\mathrm{CD}$, the values of total cholesterol were significantly lower, whereas those of C-reactive protein were significantly higher compared with healthy controls.

The fatty acid composition of plasma NEFA, PL and TAG lipids are shown in Tables 2, 3 and 4, respectively. Because nearly no significant differences were seen in plasma sterol esters, these values are not presented in tabulated form but mentioned in the text only.

\section{$S F A$}

Patients with either UC or CD had significantly lower values of palmitic acid $(16: 0)$ in plasma PL, stearic acid $(18: 0)$ and eicosanoic acid (20:0) values in plasma TAG, and total SFA in plasma PL and TAG than the corresponding values of healthy controls.

Values of 16:0 in NEFA and TAG as well as values of 18:0 in NEFA were significantly lower in patients with CD than in healthy controls. 
Table 1. Clinical characteristic of patients with ulcerative colitis and Crohn disease and healthy controls (Mean values and standard deviations)

\begin{tabular}{|c|c|c|c|c|c|c|}
\hline & \multicolumn{2}{|c|}{$\begin{array}{l}\text { Healthy control } \\
\qquad(n 24)\end{array}$} & \multicolumn{2}{|c|}{$\begin{array}{l}\text { Ulcerative colitis } \\
\qquad(n 30)\end{array}$} & \multicolumn{2}{|c|}{$\begin{array}{l}\text { Crohn disease } \\
\qquad(n 21)\end{array}$} \\
\hline & Mean & SD & Mean & SD & Mean & SD \\
\hline Gender (male/female) & $9 / 15$ & & $15 / 15$ & & $11 / 10$ & \\
\hline Age (years) & 31.5 & 8.8 & $40 \cdot 8^{\star}$ & $12 \cdot 1$ & 37.6 & $11 \cdot 0$ \\
\hline Weight (kg) & $72 \cdot 9$ & $15 \cdot 4$ & $72 \cdot 1$ & $15 \cdot 3$ & $69 \cdot 2$ & 14.7 \\
\hline Height $(\mathrm{cm})$ & $171 \cdot 2$ & $11 \cdot 7$ & $169 \cdot 8$ & 9.5 & $170 \cdot 9$ & 11.9 \\
\hline BMI $\left(\mathrm{kg} / \mathrm{m}^{2}\right)$ & $24 \cdot 6$ & 2.5 & $24 \cdot 7$ & 3.9 & 23.6 & 3.4 \\
\hline TAG $(\mathrm{mmol} / \mathrm{l})$ & 1.55 & 0.77 & 1.45 & 0.94 & 1.63 & 0.83 \\
\hline Total cholesterol (mmol/l) & $5 \cdot 61$ & 0.94 & 5.48 & $1 \cdot 20$ & $4.75^{\star}$ & 0.95 \\
\hline HDL-cholesterol (mmol/l) & 1.58 & 0.39 & 1.57 & 0.35 & 1.60 & 0.45 \\
\hline C-reactive protein (mg/l) & 3.41 & 1.61 & 8.48 & 14.01 & $12 \cdot 81^{*}$ & $12 \cdot 51$ \\
\hline Platelet count $\left(\times 1000 / \mathrm{mm}^{3}\right)$ & 288 & 39 & 279 & 76 & 287 & 66 \\
\hline
\end{tabular}

Mean values were significantly different from those of the control group: ${ }^{\star} P<0.05$.

Table 2. Fatty acid composition (\% weight per weight) of plasma NEFA in patients with ulcerative colitis, Crohn disease and healthy controls

(Median values and interquartile range)

\begin{tabular}{|c|c|c|c|c|c|c|}
\hline \multirow[b]{2}{*}{ Fatty acid } & \multicolumn{2}{|c|}{$\begin{array}{l}\text { Control } \\
\text { (n 21) }\end{array}$} & \multicolumn{2}{|c|}{$\begin{array}{l}\text { Ulcerative colitis } \\
\qquad(n 30)\end{array}$} & \multicolumn{2}{|c|}{$\begin{array}{l}\text { Crohn disease } \\
\qquad(n 24)\end{array}$} \\
\hline & Median & IQR & Median & IQR & Median & IQR \\
\hline \multicolumn{7}{|l|}{ SFA } \\
\hline $16: 0$ & 29.99 & $5 \cdot 12$ & $26 \cdot 38^{*}$ & 3.81 & $27 \cdot 34$ & 5.39 \\
\hline $18: 0$ & $12 \cdot 64$ & 3.94 & $19 \cdot 57^{*}$ & 14.07 & $16 \cdot 81$ & 8.44 \\
\hline $20: 0$ & 0.52 & 0.27 & 0.47 & 0.35 & 0.47 & 0.33 \\
\hline $\begin{array}{l}\text { Sum of SFA } \\
\text { cis-MUFA }\end{array}$ & $46 \cdot 25$ & 4.06 & $50 \cdot 26$ & $12 \cdot 63$ & $45 \cdot 36$ & $12 \cdot 69$ \\
\hline $18: 1 n-7$ & $25 \cdot 22$ & 5.06 & $26 \cdot 07$ & 8.49 & 28.37 & 6.82 \\
\hline $18: 1 n-9$ & 1.74 & 0.28 & 1.78 & 0.65 & 1.75 & 0.97 \\
\hline Sum of MUFA $\ddagger$ & 29.50 & $5 \cdot 30$ & 29.55 & 9.29 & 32.23 & 6.63 \\
\hline \multicolumn{7}{|l|}{ trans-Fatty acids } \\
\hline $16: 1, \mathrm{t}$ & 0.64 & 0.36 & 0.59 & 0.38 & 0.51 & 0.38 \\
\hline $18: 1 n-9, \mathrm{t}$ & 3.99 & 1.11 & 4.42 & 3.22 & 3.97 & 2.05 \\
\hline $18: 2 n-6, \mathrm{tt}$ & 1.01 & 0.45 & 0.95 & 0.49 & $0.79^{\star}$ & 0.43 \\
\hline $\begin{array}{l}\text { Sum of trans-fatty acids } \\
n-6 \text { PUFA }\end{array}$ & $5 \cdot 92$ & 1.47 & $6 \cdot 27$ & 3.71 & $5 \cdot 61$ & $2 \cdot 25$ \\
\hline $18: 2 n-6$ & 14.87 & 4.99 & $9.56^{\star \star}$ & 5.85 & $12 \cdot 27$ & 7.05 \\
\hline $18: 3 n-6$ & 0.16 & 0.15 & 0.21 & 0.31 & 0.15 & 0.26 \\
\hline $20: 2 n-6$ & 0.25 & 0.09 & 0.23 & 0.14 & 0.27 & 0.16 \\
\hline $20: 3 n-6$ & 0.20 & 0.09 & $0 \cdot 11^{*}$ & 0.13 & $0.13^{\star}$ & 0.15 \\
\hline $20: 4 n-6$ & 1.09 & 0.55 & $0.43^{*}$ & 0.37 & $0.56^{*}$ & 0.55 \\
\hline $22: 4 n-6$ & 0.07 & 0.08 & 0.07 & 0.07 & 0.06 & 0.07 \\
\hline Sum of $n-6$ LCPUFA§ & 1.67 & 0.59 & $1 \cdot 01^{*}$ & 0.63 & $1.09^{*}$ & 0.07 \\
\hline $\begin{array}{l}\text { Sum of } n-6 \text { PUFA } \\
n-3 \text { PUFA }\end{array}$ & $16 \cdot 78$ & $5 \cdot 89$ & $11 \cdot 15^{*}$ & $5 \cdot 68$ & $13 \cdot 23$ & $7 \cdot 67$ \\
\hline $18: 3 n-3$ & 0.26 & 0.15 & 0.24 & 0.23 & 0.27 & 0.30 \\
\hline $20: 3 n-3$ & 0.17 & 0.08 & 0.14 & 0.09 & 0.11 & 0.09 \\
\hline $20: 5 n-3$ & 0.05 & 0.08 & 0.02 & 0.08 & 0.05 & 0.05 \\
\hline $22: 5 n-3$ & 0.05 & 0.08 & 0.05 & 0.11 & 0.06 & 0.06 \\
\hline $22: 6 n-3$ & 0.11 & 0.10 & 0.09 & 0.11 & 0.08 & 0.13 \\
\hline Sum of $n-3$ LCPUFA & 0.44 & 0.29 & 0.37 & 0.30 & 0.32 & 0.43 \\
\hline 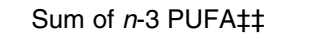 & 0.71 & 0.37 & 0.62 & 0.43 & 0.72 & 0.50 \\
\hline
\end{tabular}

IQR, interquartile range; LCPUFA, long-chain PUFA.

Mean values were significantly different from those of the control group: ${ }^{*} P<0.05$; ${ }^{\star *} P<0.001$.

‡Sum of MUFA $=16: 1 n-7+18: 1 n-7+18: 1 n-9+20: 1 n-9+22: 1 n-9+24: 1 n-9$.

§ Sum of $n-6$ LCPUFA $=20: 2 n-6+20: 3 n-6+20: 4 n-6+22: 4 n-6+22: 5 n-6$

$\|$ Sum of $n-6$ PUFA $=$ sum of $n-6$ LCPUFA $+18: 2 n-6+18: 3 n-6$.

1 Sum of $n-3$ LCPUFA $=20: 3 n-3+20: 5 n-3+22: 5 n-3+22: 6 n-3$.

$\ddagger$ Sum of $n-3$ PUFA $=$ sum of $n-3$ LCPUFA $+18: 3 n-3$. 
Table 3. Fatty acid composition of plasma TAG in patients with ulcerative colitis, Crohn disease (CD) and healthy controls (Median values and interquartile range)

\begin{tabular}{|c|c|c|c|c|c|c|}
\hline \multirow[b]{2}{*}{ Fatty acid } & \multicolumn{2}{|c|}{ Control (n 21) } & \multicolumn{2}{|c|}{ Ulcerative colitis ( $n 30)$} & \multicolumn{2}{|c|}{ Crohn disease ( $n$ 24) } \\
\hline & Median & IQR & Median & IQR & Median & IQR \\
\hline \multicolumn{7}{|l|}{ SFA } \\
\hline $16: 0$ & 31.31 & 6.97 & $25 \cdot 45^{\star}$ & 4.44 & 27.42 & 7.99 \\
\hline $18: 0$ & 7.93 & 3.78 & $4 \cdot 82^{\star *}$ & 1.93 & $4.67^{\star \star}$ & 0.95 \\
\hline $20: 0$ & 0.32 & 0.28 & $0.21^{\star \star}$ & 0.06 & $0 \cdot 19^{\star \star}$ & 0.07 \\
\hline Sum of SFA & 42.04 & $10 \cdot 06$ & $33 \cdot 10^{\star \star}$ & 5.08 & $33 \cdot 50^{\star}$ & 7.68 \\
\hline \multicolumn{7}{|l|}{ cis-MUFA } \\
\hline $18: 1 n-7$ & 32.69 & 4.99 & $36 \cdot 31^{\star *}$ & 5.25 & $36 \cdot 70^{*}$ & 5.77 \\
\hline $18: 1 n-9$ & 1.74 & 0.50 & 1.93 & 0.40 & $1 \cdot 79$ & 0.78 \\
\hline Sum of MUFOA & 37.01 & $4 \cdot 31$ & $41 \cdot 14^{\star \star}$ & 5.13 & $41 \cdot 19^{*}$ & 5.04 \\
\hline \multicolumn{7}{|l|}{ trans-Fatty acids } \\
\hline $16: 1, \mathrm{t}$ & 0.81 & 0.21 & 0.73 & 0.41 & 0.69 & 0.35 \\
\hline $18: 1 n-9, \mathrm{t}$ & 5.00 & $2 \cdot 40$ & $2 \cdot 71^{\star}$ & $2 \cdot 12$ & $1.97^{\star \star}$ & 1.79 \\
\hline $18: 2 n-6, \mathrm{tt}$ & 1.03 & 0.46 & $0.59^{*}$ & 0.56 & $0.67^{\star}$ & 0.44 \\
\hline Sum of trans-fatty acids & $6 \cdot 71$ & $2 \cdot 67$ & $4 \cdot 33^{\star *}$ & $2 \cdot 65$ & $2 \cdot 95^{\star \star}$ & $2 \cdot 39$ \\
\hline \multicolumn{7}{|l|}{$n-6$ PUFA } \\
\hline $18: 2 n-6$ & 11.14 & $8 \cdot 36$ & $19 \cdot 19^{*}$ & 5.52 & $17 \cdot 81^{*}$ & 7.40 \\
\hline $18: 3 n-6$ & 0.13 & $0 \cdot 10$ & 0.20 & 0.22 & $0.23^{*}$ & 0.15 \\
\hline $20: 2 n-6$ & 0.16 & 0.07 & $0.25^{\star \star}$ & 0.08 & $0.27^{\star}$ & 0.13 \\
\hline $20: 3 n-6$ & 0.09 & 0.05 & $0.15^{\star \star}$ & 0.08 & $0 \cdot 16^{\star}$ & 0.10 \\
\hline $20: 4 n-6$ & 0.42 & 0.24 & $0.62^{* *}$ & 0.31 & $0.77^{\star *}$ & 0.32 \\
\hline $22: 4 n-6$ & 0.04 & 0.02 & $0.06^{* *}$ & 0.02 & $0.09^{\star \star}$ & 0.03 \\
\hline Sum of $n-6$ LCPUFA $\S$ & 0.76 & 0.30 & $1 \cdot 12^{\star *}$ & 0.37 & $1 \cdot 24^{\star *}$ & 0.39 \\
\hline Sum of $n-6$ PUFA\| & 11.88 & $8 \cdot 71$ & $20 \cdot 80^{\star *}$ & 5.75 & $20 \cdot 00^{*}$ & 7.02 \\
\hline \multicolumn{7}{|l|}{$n-3$ PUFA } \\
\hline $18: 3 n-3$ & 0.20 & 0.16 & 0.23 & 0.11 & $0.27^{\star}$ & 0.17 \\
\hline $20: 3 n-3$ & 0.04 & 0.03 & 0.07 & 0.05 & 0.06 & 0.03 \\
\hline $20: 5 n-3$ & 0.01 & 0.01 & $0.02^{*}$ & 0.02 & $0.03^{\star \star}$ & 0.02 \\
\hline $22: 5 n-3$ & 0.01 & 0.02 & $0.05^{\star *}$ & 0.04 & $0.06^{\star \star}$ & 0.03 \\
\hline $22: 6 n-3$ & 0.04 & 0.02 & $0.07^{\star *}$ & 0.04 & $0.05^{\star}$ & 0.05 \\
\hline Sum of $n-3$ LCPUFA & 0.11 & $0 \cdot 10$ & $0.20^{* *}$ & 0.14 & $0.25^{\star \star}$ & 0.11 \\
\hline Sum of $n-3$ PUFA $\neq \ddagger$ & 0.31 & 0.20 & $0.45^{\star}$ & 0.24 & $0.53^{*}$ & 0.26 \\
\hline
\end{tabular}

IQR, interquartile range; LCPUFA, long-chain PUFA.

Mean values were significantly different from those of the control group: ${ }^{\star} P<0.05 ;{ }^{\star \star} P<0.001$.

$\ddagger$ Sum of MUFA $=16: 1 n-7+18: 1 n-7+18: 1 n-9+20: 1 n-9+22: 1 n-9+24: 1 n-9$.

$\S$ Sum of $n-6$ LCPUFA $=20: 2 n-6+20: 3 n-6+20: 4 n-6+22: 4 n-6+22: 5 n-6$.

$\|$ Sum of $n-6$ PUFA $=$ sum of $n-6$ LCPUFA $+18: 2 n-6+18: 3 n-6$.

1 Sum of $n-3$ LCPUFA $=20: 3 n-3+20: 5 n-3+22: 5 n-3+22: 6 n-3$

拉 Sum of $n-3$ PUFA $=$ sum of $n-3$ LCPUFA $+18: 3 n-3$.

\section{cis-MUFA}

Values of vaccenic acid $(18: 1 n-7)$ and those of total MUFA in plasma TAG were significantly higher in patients with UC and $\mathrm{CD}$ than in controls.

\section{Trans-isomeric fatty acids}

Compared with healthy controls, values of trans-octadecadienoic acid $(18: 2 n-6, t \mathrm{t})$ were significantly lower in patients with UC and CD in plasma PL and TAG and in patients with CD in plasma NEFA. Values of trans-octadecenoic acid $(18: 1 n-9, \mathrm{t})$ and values of total trans-isomeric fatty acids were significantly lower in patients with UC and CD in plasma TAG compared with healthy controls.

\section{n-6 PUFA}

In plasma PL, the values of $\gamma$-linolenic acid $(18: 3 n-6)$ and docosatetraenoic acid $(22: 4 n-6)$ were significantly higher in patients with $\mathrm{UC}$ and $\mathrm{CD}$ than in the controls, whereas the values of $20: 4 n-6$ and the sum of $n-6$ PUFA were significantly higher in patients with UC only. In plasma TAG, values of linoleic acid (18:2n-6), eicosadienoic acid (20:2n-6), dihomo- $\gamma$-linolenic acid (20:3n-6), 20:4n-6, $22: 4 n-6$, the sum of $n-6$ PUFA and the sum of $n-6$ longchain PUFA (LCPUFA) were significantly higher in patients with UC and CD compared with healthy controls. In contrast, a different picture was seen in plasma NEFA, where the values of $20: 3 n-6,20: 4 n-6$ and the sum of LCPUFA were significantly lower in patients with UC and CD than in healthy controls. Values of $18: 2 n-6$ and the sum of $n-6$ PUFA were also significantly lower in patients with UC compared with healthy controls in plasma NEFA. Values of $20: 2 n-6$ and $20: 3 n-3$ were significantly lower in patients with UC compared with healthy controls in plasma sterol esters (data not shown).

\section{n-3 PUFA}

In plasma PL, docosatrienoic acid $(20: 3 n-3)$ values were significantly higher in patients with UC and CD and $22: 6 n-3$ values were higher in patients with UC compared with control subjects. In plasma TAG, values of $\alpha$-linolenic acid (18:3n-3) 
Table 4. Fatty acid composition of plasma phospholipids in patients with ulcerative colitis, Crohn disease and healthy controls

(Median values and interquartile range)

\begin{tabular}{|c|c|c|c|c|c|c|}
\hline \multirow[b]{2}{*}{ Fatty acid } & \multicolumn{2}{|c|}{$\begin{array}{l}\text { Control } \\
\text { (n 21) }\end{array}$} & \multicolumn{2}{|c|}{$\begin{array}{l}\text { Ulcerative colitis } \\
\qquad(n 30)\end{array}$} & \multicolumn{2}{|c|}{$\begin{array}{l}\text { Crohn disease } \\
\quad(n 24)\end{array}$} \\
\hline & Median & IQR & Median & IQR & Median & IQR \\
\hline \multicolumn{7}{|l|}{ SFA } \\
\hline $16: 0$ & 35.92 & 4.42 & $31.47^{\star \star}$ & 3.46 & $32 \cdot 65^{*}$ & 3.41 \\
\hline $18: 0$ & 17.59 & 2.48 & $17 \cdot 28$ & $2 \cdot 12$ & $16 \cdot 69$ & 1.74 \\
\hline $20: 0$ & 0.66 & $0 \cdot 13$ & 0.62 & 0.25 & 0.67 & 0.39 \\
\hline Sum of SFA & $55 \cdot 46$ & 4.87 & $52 \cdot 17^{\star \star}$ & 3.87 & $52 \cdot 03^{*}$ & 4.93 \\
\hline \multicolumn{7}{|l|}{ cis-MUFA } \\
\hline $18: 1 n-7$ & 78.33 & 1.72 & 8.25 & $1 \cdot 24$ & $8 \cdot 78$ & 1.03 \\
\hline $18: 1 n-9$ & 1.06 & $0 \cdot 19$ & $1 \cdot 18$ & 0.31 & 1.08 & 0.37 \\
\hline Sum of MUFA & 11.44 & 1.44 & $11 \cdot 84$ & 2.06 & $12 \cdot 18$ & 1.90 \\
\hline \multicolumn{7}{|l|}{ trans-Fatty acids } \\
\hline $16: 1, t$ & $0 \cdot 13$ & 0.03 & 0.12 & 0.05 & $0 \cdot 13$ & 0.04 \\
\hline $18: 1 n-9, \mathrm{t}$ & 0.49 & 0.19 & 0.44 & 0.52 & 0.43 & 0.37 \\
\hline $18: 2 n-6, \mathrm{tt}$ & 0.33 & $0 \cdot 16$ & $0.22^{*}$ & $0 \cdot 18$ & $0.22^{*}$ & $0 \cdot 15$ \\
\hline Sum of trans-fatty acids & 1.00 & 0.32 & 0.88 & 0.69 & 0.71 & 0.53 \\
\hline \multicolumn{7}{|l|}{$n-6$ PUFA } \\
\hline $18: 2 n-6$ & $19 \cdot 91$ & 5.67 & 21.57 & 7.49 & $19 \cdot 71$ & 4.44 \\
\hline $18: 3 n-6$ & 0.02 & 0.02 & $0.03^{*} \dagger$ & 0.02 & $0.05^{\star \star}$ & 0.03 \\
\hline $20: 2 n-6$ & 0.42 & 0.15 & 0.38 & $0 \cdot 10$ & 0.37 & $0 \cdot 15$ \\
\hline $20: 3 n-6$ & 2.06 & 0.79 & $2 \cdot 11$ & 0.93 & $2 \cdot 01$ & 1.00 \\
\hline $20: 4 n-6$ & 6.92 & 2.96 & $8.43^{*}$ & $3 \cdot 23$ & 8.02 & 3.85 \\
\hline $22: 4 n-6$ & 0.15 & 0.10 & $0.22^{\star \star}$ & 0.14 & $0.26^{\star \star}$ & 0.13 \\
\hline Sum of $n-6$ LCPUFA§ & 9.65 & 3.33 & 11.42 & $4 \cdot 30$ & 10.79 & 3.44 \\
\hline \multirow{2}{*}{\multicolumn{7}{|c|}{$n-3$ PUFA }} \\
\hline & & & & & & \\
\hline $18: 3 n-3$ & 0.05 & 0.04 & 0.06 & 0.03 & 0.07 & 0.04 \\
\hline $20: 3 n-3$ & 0.27 & 0.08 & $0.21^{*}$ & 0.08 & $0.21^{*}$ & 0.06 \\
\hline $20: 5 n-3$ & 0.09 & 0.05 & $0.14^{\star}$ & $0 \cdot 10$ & $0.16^{\star}$ & $0 \cdot 10$ \\
\hline $22: 5 n-3$ & 0.14 & $0 \cdot 10$ & $0.27^{\star \star}$ & $0 \cdot 16$ & $0.31^{\star \star}$ & $0 \cdot 10$ \\
\hline $22: 6 n-3$ & 0.73 & 0.39 & $1 \cdot 22^{*}$ & 0.56 & 0.92 & 0.82 \\
\hline Sum of $n-3$ LCPUFA & 1.26 & 0.48 & $1.96^{*}$ & 0.79 & $1.73^{*}$ & 1.11 \\
\hline Sum of $n-3$ PUFA $\ddagger$ & 1.33 & 0.47 & $2 \cdot 01^{\star \star}$ & 0.79 & $1.64^{*}$ & $1 \cdot 10$ \\
\hline
\end{tabular}

IQR, interquartile range; LCPUFA, long-chain PUFA.

Mean values were significantly different from those of the control group: ${ }^{*} P<0.05 ;{ }^{\star \star} P<0.001$

Mean value was significantly different from that of the Crohn disease group: $\dagger P<0.05$.

$\ddagger$ Sum of MUFA $=16: 1 n-7+18: 1 n-7+18: 1 n-9+20: 1 n-9+22: 1 n-9+24: 1 n-9$.

$\S$ Sum of $n-6$ LCPUFA $=20: 2 n-6+20: 3 n-6+20: 4 n-6+22: 4 n-6+22: 5 n-6$.

IS Sum of $n-6$ PUFA $=$ sum of $n-6$ LCPUFA $+18: 2 n-6+18: 3 n-6$

1 Sum of $n-3$ LCPUFA $=20: 3 n-3+20: 5 n-3+22: 5 n-3+22: 6 n-3$.

¥† Sum of $n-3$ PUFA $=$ sum of $n-3$ LCPUFA $+18: 3 n-3$.

were significantly higher in patients with $\mathrm{CD}$ and values of $22: 6 n-3$ were significantly higher in patients both with UC and CD compared with healthy subjects. In plasma PL and TAG, values of $20: 5 n-3$, docosapentoic acid $(22: 5 n-3)$, the sum of $n-3$ LCPUFA and the sum of $n-3$ PUFA were significantly higher in patients with UC and CD than in healthy controls.

\section{Ratios}

In plasma NEFA, the ratios of $20: 4 n-6 / 20: 3 n-6$ and $20: 4 n-6 /$ $18: 2 n-6$ were significantly lower in patients with UC and CD compared with healthy controls (Fig. 1). In plasma NEFA and PL, the ratios of $n-6 / n-3$ LCPUFA were significantly lower in patients with UC compared with healthy controls (Fig. 2). In plasma PL, the $n-6 / n-3$ PUFA ratios were significantly lower in patients with UC than in healthy controls (17.83 (SD 8.49) $v$. 20.99 (SD 9.63), $P<0.05$ ). No significant differences were seen in the ratios in the other three lipid classes investigated.

\section{Discussion}

IBD is a condition known to be accompanied by various nutritional disturbances including impaired LCPUFA status. The potentially reduced availibility of certain LCPUFA may be of particular significance because they are known to be integral parts of cell membranes and they are precursors of important eicosanoids, which participate in inflammatory responses. The hypothesis has been put forward that changes in the metabolism of LCPUFA in IBD may be of relevance in maintaining the chronic inflammatory condition (Kuroki et al. 1997).

Contradictory findings concerning the availability LCPUFA in CD were reported both in adult patients and children. As far as the paediatric age-group is concerned, Socha et al. (2005) recently reported significantly lower values of $18: 2 n-6$ and $20: 4 n-6$ in children with IBD compared with healthy controls, while values of $18: 3 n-3$ were higher in patients than in controls. Levy et al. (2000) found significantly lower values of $18: 2 n-6$ in children with CD compared with healthy controls. 
(A)

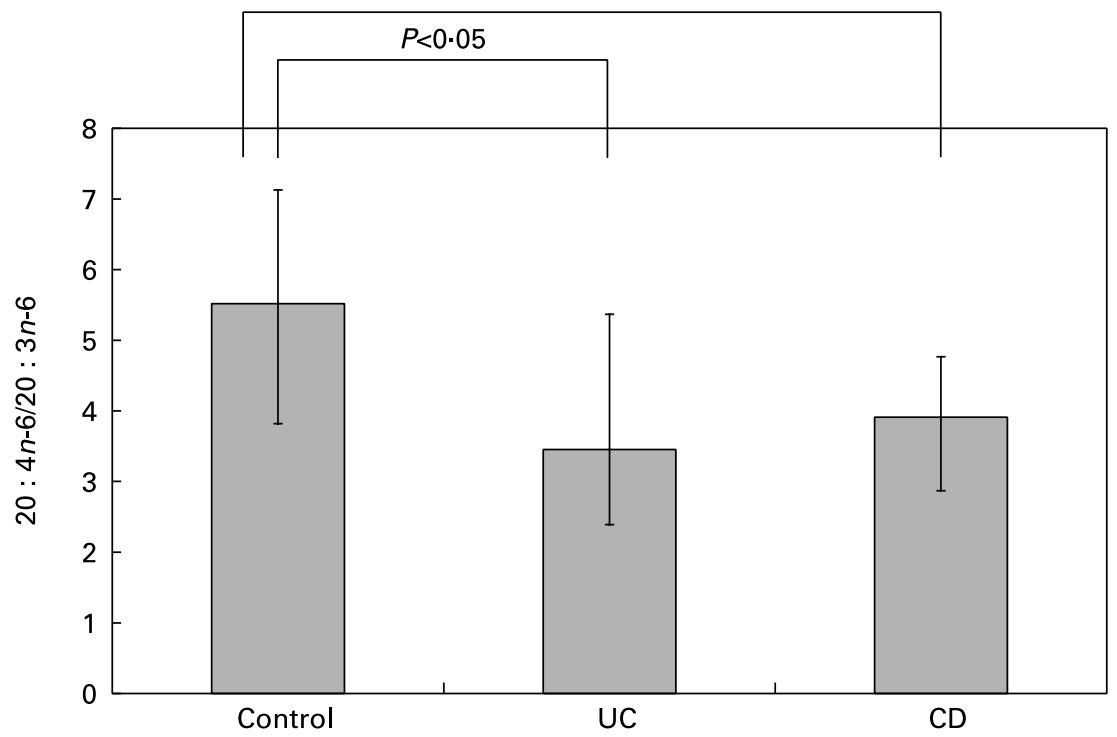

(B)

$P<0.05$

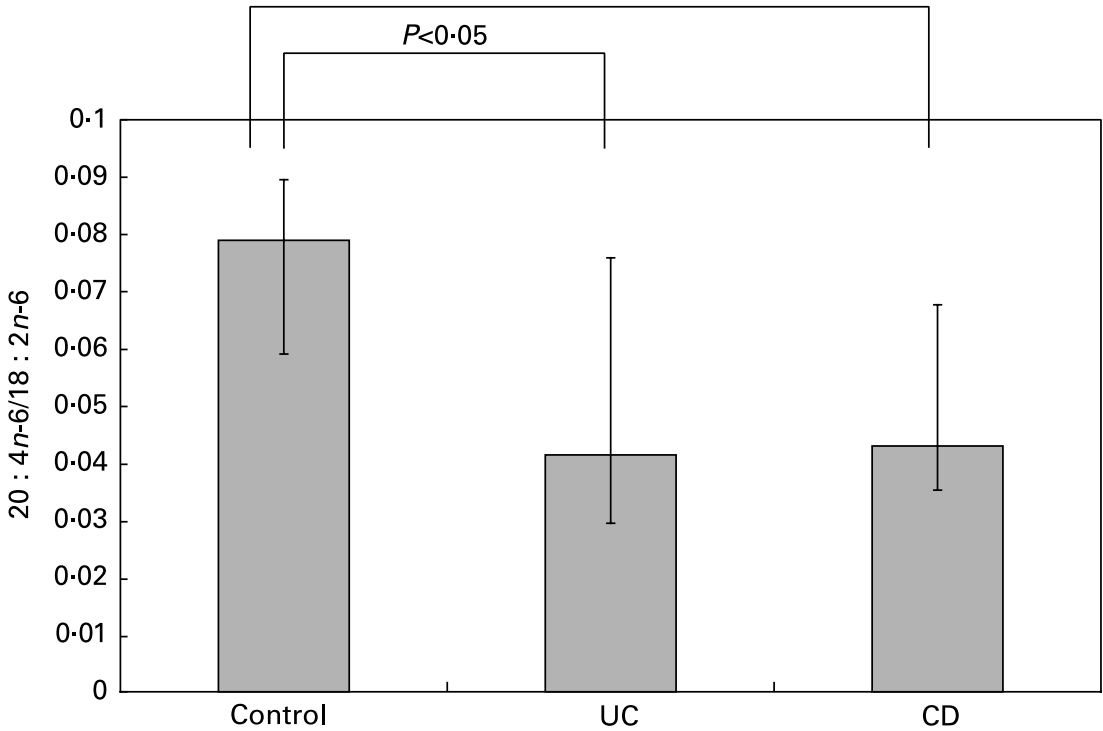

Fig. 1. The ratio of arachidonic acid $(20: 4 n-6)$ to dihomo- $\gamma$-linolenic acid $(20: 3 n-6)(A)$ and the ratio of $20: 4 n-6$ to linoleic acid (18:2n-6) (B) in NEFA in patients suffering from ulcerative colitis (UC, $n 30)$ or Crohn disease (CD, $n 24)$ and in healthy controls $(n 21)$. Values are median with the interquartile range depicted by vertical bars.

To complicate matters, Trebble et al. (2003) reported lower $18: 2 n-6$ and $18: 3 n-3$ values in children with active than in those with inactive $\mathrm{CD}$; unfortunately, the values of patients were not compared with those of healthy children.

As far as adult patients are concerned, Siguel \& Lerman (1996) found higher values of SFA and MUFA, but lower values of $n-3$ and $n$-6 PUFA in patients with various chronic intestinal disorders compared with control subjects. Kuroki et al. (1997) reported lower serum values of $20: 4 n-6$, $20: 5 n-3$ and $22: 6 n-3$, as well as a significantly increased ratio of $n$-6 PUFA to $n-3$ PUFA in patients with CD when compared to controls.
In contrast, Esteve-Comas et al. (1992) reported elevated plasma values of $18: 3 n-3$ and $22: 6 n-3$ and decreased values of $20: 3 n-6$ in active IBD patients compared to controls.

Later on, Esteve-Comas et al. (1993) reported significantly increased $n$-3 LCPUFA values in patients both with IBD and $\mathrm{CD}$, together with significantly increased values of $n-6$ LCPUFA in inactive patients with UC compared with controls.

It is to be noted that fatty acid composition of plasma total lipids has been used as indicator of fatty acid status in many previous studies (Esteve-Comas et al. 1992, 1993; Siguel \& 


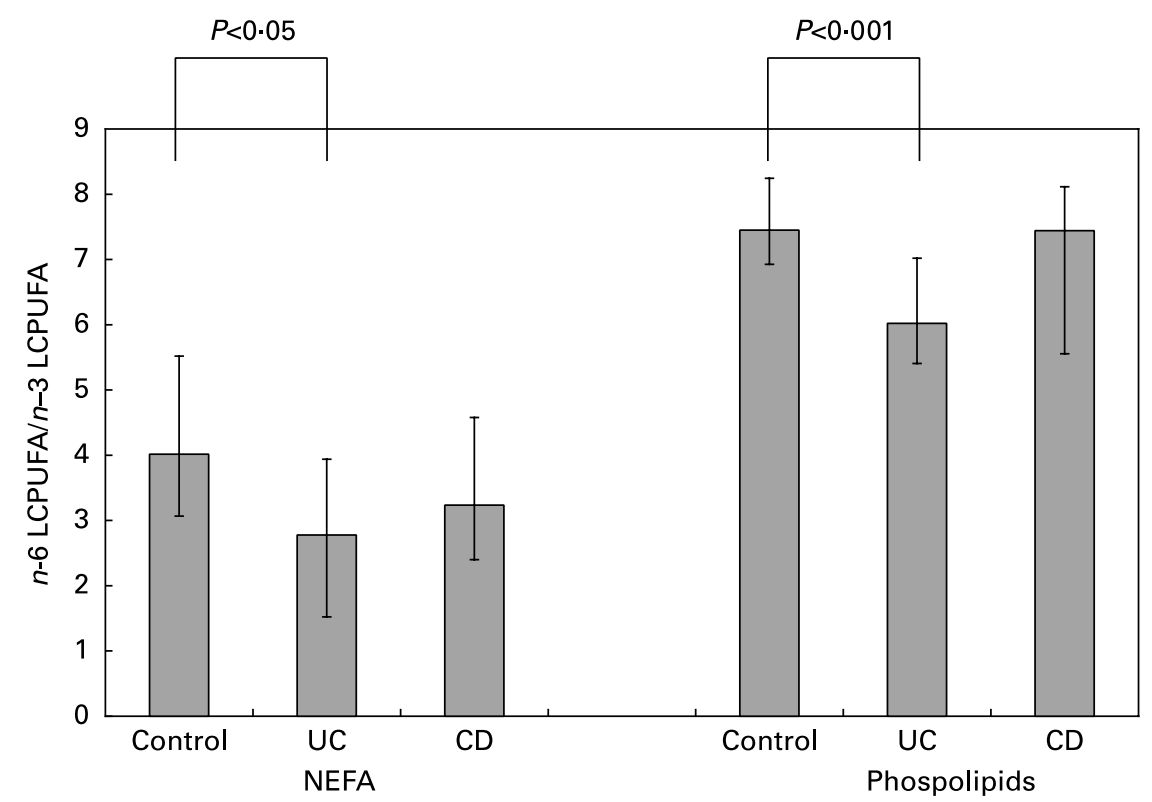

Fig. 2. The ratio of $n-6$ to $n-3$ long-chain PUFA (LCPUFA) in plasma NEFA and phospholipids in patients suffering from ulcerative colitis (UC, $n$ 30) or Crohn disease (CD, $n 24)$ and in healthy controls $(n 21)$. Values are median with the interquartile range depicted by vertical bars.

Lerman, 1996; Kuroki et al. 1997; Levy et al. 2000), and dyslipidaemia may profoundly influence that parameter. In the present study, we investigated plasma lipid classes separated by TLC. Nevertheless, the results obtained in the present study showed also significant differences in plasma fatty acid patterns in patients with IBD compared to healthy controls. However, somewhat different pictures were seen in lipids with different biological roles. In either plasma PL and TAG, significantly higher values of various $n-3$ and $n-6$ LCPUFA including the eicosanoid precursors (20:5n-3, $20: 3 n-6$ and $20: 4 n-6$ ), which may play an important role in the pathogenesis of IBD, were seen in patients with either $\mathrm{UC}$ or CD as compared to controls. Though a different picture was seen in NEFA, namely significantly lower values of both $20: 3 n-6$ and $20: 4 n-6$ in patients either with UC or CD than in controls; however, the contributions of LCPUFA to NEFA is much smaller than to PL. Hence, the data obtained in the present study do not support the concept of the deficiency of PUFA or LCPUFA in patients with IBD.

Previous studies reporting significantly lower values of $n-3$ PUFA in patients with IBD than in controls (Siguel \& Lerman, 1996; Kuroki et al. 1997) gave rise to dietary interventions with fish oil rich in 20:5n-3 and 22:6n-3 (Lorenz et al. 1989; Aslan \& Triadafilopoulos, 1992; Hawthorne et al. 1992; Stenson et al. 1992). However, the studies investigating the effects of $n-3$ PUFA supplementation in IBD patients yielded partly contradictory results. On the one hand, the steroid-sparing effect (Aslan \& Triadafilopoulos, 1992; Hawthorne et al. 1992), significantly improved activity score of the disease (Aslan \& Triadafilopoulos, 1992), significant gain in body weight (Stenson et al. 1992) indicated clinical benefits of supplementation. On the other hand, no significant steroid-sparing effect (Stenson et al. 1992), failure in prevention of clinical relapse (Hawthorne et al. 1992) and unchanged clinical activity (Lorenz et al. 1989) were also described.
The contradictory findings of the various studies reported may be due to methologic differences, the different activity of the disease in the patients studied, or different nutritient intakes of the patients.

Eicosanoid synthesis utilises NEFA, i.e. the NEFA pool of plasma lipids may provide some information on the demand of eicosanoid precursors. In the present study, both $20: 3 n-6$ and $20: 4 n-6$ values were significantly lower in patients with IBD than in controls.

Moreover, the $n-6$ to $n-3$ PUFA ratio, thought to be related to the availability of precursors for inflammatory and antiinflammatory eicosanoid production, was significantly lower in patients with UC than in controls. It is tempting to speculate that patients with IBD utilised more $20: 4 n-6$ than controls. Indeed the significantly lower ratios of $20: 4 n-6$ to $20: 3 n-6$ and $20: 4 n-6$ to $18: 2 n-6$ appear to support this concept.

In summary, the data obtained in the present study indicate not reduced but abundant contribution of both $n-6$ and $n-3$ LCPUFA to the major plasma lipid classes together with some indirect sign of enhanced utilisation of $n-6$ LCPUFA in patients with IBD. Hence, reduction of dietary $n-6$ PUFA intakes may be an alternative to $n-3$ LCPUFA supplementation in attempting to modify inflammatory processes in IBD.

\section{Acknowledgements}

The project was supported in part by the Hungarian National Research Fund (OTKA T046630 for T. D.).

\section{References}

Aslan A \& Triadafilopoulos G (1992) Fish oil fatty acid supplementation in active ulcerative colitis: a double-blind, placebo-controlled, crossover study. Am J Gastroenterol 87, 432-437. 
Belluzzi A (2004) Polyunsaturated fatty acids ( $n$-3 PUFA) and inflammatory bowel disease (IBD): pathogenesis and treatment. Eur Rev Med Pharmacol Sci 8, 225-229.

Decsi T, Molnár D \& Koletzko B (1998) The effect of under- and overnutrition on essential fatty acid metabolism in childhood. Eur J Clin Nutr 52, 541-548.

Esteve-Comas M, Núňez MC, Fernández-Banares F, Abad-Lacruz A, Gil A, Cabré E, González-Huix F, Bertrán X \& Gassull MA (1993) Abnormal plasma polyunsaturated fatty acid pattern in non-active inflammatory bowel disease. Gut 34, 1370-1373.

Esteve-Comas M, Ramírez M, Fernández-Banares F, et al. (1992) Plasma polyunsaturated fatty acid pattern in active inflammatory bowel disease. Gut 33, 1365-1369.

Gil Á (2002) Polyunsaturated fatty acids and inflammatory diseases. Biomed Pharmacother 56, 388-396.

Han PD, Burke A, Baldassano RN, Rombeau JL \& Lichtenstein GR (1999) Nutrition and inflammatory bowel disease. Gastroenterol Clin North Am 28, 423-443.

Hawthorne AB, Daneshmend TK, Hawkey CJ, et al. (1992) Treatment of ulcerative colitis with fish oil supplementation: a prospective 12 month randomized controlled trial. Gut 33, 922-928.

Kuroki F, Iida M, Matsumoto T, Aoyagi K, Kanamoto K \& Fujishima M (1997) Serum $n-3$ polyunsaturated fatty acids are depleted in Crohn's disease. Dig Dis Sci 42, 1137-1141.

Levy E, Rizwan Y, Thibault L, Lepage G, Brunet L, Bouthillier L \& Seidman E (2000) Altered lipid profile, lipoprotein composition, and oxidant and antioxidant status in pediatric Crohn disease. Am J Clin Nutr 71, 807-815.
Lorenz R, Weber PC, Szimnau P, et al. (1989) Supplementation with $n-3$ fatty acids from fish oil in chronic inflammatory bowel disease - a randomized placebo-controlled, double-blind cross-over trial. $J$ Int Med 225, 225-232.

Shoda R, Matsueda K, Yamato S, Umeda N \& Shanahan F (1996) Epidemiologic analysis of Crohn disease in Japan increased dietary intake of $n-6$ polyunsaturated fatty acids and animal protein relates to the increased incidence of Crohn disease in Japan. Am J Clin Nutr 63, 741-745.

Siguel EN \& Lerman RH (1996) Prevalence of essential fatty acid deficiency in patients with chronic gastrointestinal disorders. Metabolism 45, 12-23.

Socha P, Ryzko J, Koletzko B, Celinska-Cedro D, Woynarowski M, Czubkowski P \& Socha J (2005) Essential fatty acid depletion in children with inflammatory bowel disease. Scand J Gastroenterol 40, 573-577.

Steele RW, Rochler DF \& Azar M (1976) Enzymatic determination of cholesterol in high density lipoprotein fractions prepared by precipitation technique. Clin Chem 22, 98-102.

Stenson WF, Cort D, Rodgers J, et al. (1992) Dietary supplementation with fish oil in ulcerative colitis. Ann Intern Med 116, 609-614.

Teitelbaum JE \& Walker WA (2001) Review: the role of omega 3 fatty acids in intestinal inflammation. $J$ Nutr Biochem 12, 21-32.

Trebble TM, Wootton SA, May A, Erlewyn-Lajeunesse MD, Chakraborty A, Mullee MA, Stroud MA \& Beattie RM (2003) Essential fatty acid status in pediatric Crohn's disease: relationship with disease activity and nutritional status. Aliment Pharmacol Ther 18, 433-442. 